\title{
Importância do zinco na nutrição humana
}

\section{The importance of zinc in human nutrition}

Denise MAFRA ${ }^{1}$

Sílvia Maria Franciscato COZZOLINO ${ }^{1}$

RE S U M O

Recentes pesquisas experimentais e clínicas têm reforçado a importância do zinco na saúde humana. 0 zinco possibilita várias funções bioquímicas, pois é componente de inúmeras enzimas, dentre estas, álcool desidrogenase, superóxido dismutase, anidrase carbônica, fosfatase alcalina e enzimas do sistema nervoso central. Participa na divisão celular, expressão genética, processos fisiológicos como crescimento e desenvolvimento, na transcrição genética, na morte celular, age como estabilizador de estruturas de membranas e componentes celulares, além de participar da função imune e desenvolvimento cognitivo. Sua deficiência pode causar alterações fisiológicas como, hipogonodismo, danos oxidativos, alterações do sistema imune, hipogeusia, danos neuropsicológicos e dermatites. Assim, devido a inúmeras pesquisas referentes a este mineral, este trabalho teve como objetivo mostrar os aspectos atuais sobre a essencialidade do zinco na nutrição humana.

Termos de indexação: zinco, nutrição, morte celular, processos fisiológicos, saúde.

\section{A B S T R A C T}

Recent clinical and experimental findings have reinforced the importance of zinc in human nutrition. Zinc plays a key role in the function of several enzymes like alcohol dehydrogenase, copper-zinc superoxide dismutase, carbonic anhydrase, alkaline phosphatase, ribonucleic acid polymerase and enzymes in the central nervous system. Zinc also participates in cell division, genetic expression, physiological processes like growth and development, genetic transcription, as well as programmed cell death, acting in the stabilization of biomembrane structures and cellular components. Furthermore, zinc affects the immune function and cognitive development. Effects of its deficiency include hypogonadism, oxidative damage, and alterations in the immune system, hypogeusia, neuropsychological impairment and dermatitis. In view of the abundant research on this mineral, this study had the objective of divulging more recent literature supporting the concept that zinc is essential in human nutrition.

Index terms: zinc, nutrition, cell death, physiological process, health.

\footnotetext{
${ }^{1}$ Departamento Alimentos e N utrição Experimental, Faculdade de Ciências Farmacêuticas, Universidade de São Paulo. Av. Lineu Prestes, 580 - Bloco 14, 05508-030, São Paulo, SP, Brasil. Correspondência para/Correspondence to: D.MAFRA. E-mail: dmafra@terra.com.br
} 


\section{N T R O D U Ç Ã O}

Como um componente estrutural e/ou funcional de várias metaloenzimas e metaloproteínas, o zinco participa de muitas reações do metabolismo celular, incluindo processos fisiológicos, tais como função imune, defesa antioxidante, crescimento e desenvolvimento ${ }^{1}$.

0 entendimento das funções do zinco no metabolismo teve início em 1869 com Raulin, que descobriu sua essencialidade para Aspergillus niger. Quarenta anos mais tarde, Mazé descreveu problemas no cultivo de milho pela falta de zinco. Todd, Evehjem e Hart, em 1934, descobriram sua essencialidade para ratos, e, mais tarde, em 1955, Tucker e Salmon descobriram problemas na pele do ser humano, decorrentes da deficiência de zinco. Em 1960, O'Dell observou que este mineral era essencial para crianças. Vários estudos se seguiram demonstrando que a deficiência de zinco era revertida pela suplementação².

\section{Bases bioquímicas}

0 zinco ( $\mathrm{Zn}$ ) difere dos outros metais de transição, pois contém a camada eletrônica " $d$ " completa e assim não participa de reações redox, mas age como ácido de Lewis para aceitar um par de elétrons, fazendo com que seja um íon estável. 0 zinco ocorre naturalmente como 5 isótopos estáveis: ${ }^{64} \mathrm{Zn},{ }^{66} \mathrm{Zn},{ }^{67} \mathrm{Zn},{ }^{68} \mathrm{Zn}$, e ${ }^{70} \mathrm{Zn}$. Geralmente se complexa com aminoácidos, peptídios e nucleotídeos e tem afinidade com grupos tióis e hidrogênio³.

\section{Recomendações Nutricionais e Fontes}

A recomendação deste nutriente para a população sadia, foi modificada recentemente para $8 \mathrm{mg} /$ dia para mulheres e $11 \mathrm{mg} /$ dia para homens ${ }^{4}$.

Os alimentos diferem no seu conteúdo de $\mathrm{Zn}$, variando de $0,002 \mathrm{mg} / 100 \mathrm{~g}$ de clara de ovo, $1 \mathrm{mg} / 100 \mathrm{~g}$ de frango até $75 \mathrm{mg} / 100 \mathrm{~g}$ de ostras. M ariscos, ostras, carnes vermelhas, fígado, miúdos e ovos são consideradas as melhores fontes de zinco. Nozes e leguminosas são fontes relativamente boas de zinco. 0 consumo de zinco é influenciado pela fonte protéica da dieta, assim, dietas constituídas de ovos, leite, frango e peixe têm menor razão $\mathrm{Zn}$ :Proteína do que aquelas de mariscos, ostras e carnes vermelhas ${ }^{5}$.

\section{Metabolismo}

Partindo do princípio que a simples presença do nutriente na dieta não garante sua utilização pelo organismo, devemos abordar alguns fatores que podem afetar a biodisponibilidade do zinco na dieta.

As boas fontes de zinco não contém constituintes químicos que inibem a absorção do zinco, e, além disto, a presença de alguns aminoácidos, como cisteína e histidina melhoram a sua solubilidade.

O conteúdo de fitato presente nos alimentos reduz a biodisponibilidade de $\mathrm{Zn}$. A razão molar fitato:Zn de 20 já pode produzir efeito negativo, pois o fitato é carregado negativamente; logo, tem um forte potencial para ligar cátions bivalentes, tais como o zinco, impedindo assim sua absorção $0^{6,7}$.

Existem fatores intraluminais facilitadores da absorção de zinco como: aminoácidos (histidina e metionina), fosfatos, ácidos orgânicos e algumas prostaglandinas. A quantidade de proteína da refeição tem efeito positivo na absorção do zinco, porém proteínas específicas como a caseína tem efeito inibitório na absorção ${ }^{8}$.

Outros componentes de alimentos como fibras, taninos e cafeína parecem não afetar a utilização de zinco pelo organismo, porém Dyck et al. ${ }^{9}$, estudando in vitro a disponibilidade de Fe, Ca e Zn de uma refeição contendo 4 componentes alimentares diferentes (café, vitamina $\mathrm{C}$, farinha de trigo e pectina), observaram que com exceção da vitamina $\mathrm{C}$, todos os demais componentes tiveram efeitos negativos na disponibilidade desses minerais, sendo que o maior efeito foi da farinha 
de trigo, e o Zn foi o elemento traço que sofreu maior interferência. 0 ferro, se fornecido junto com $\mathrm{Zn}$ através de suplemento pode ter efeito negativo na absorção do $\mathrm{Zn}^{8}$.

Lee et al. $(1989)^{10}$, demonstraram, em um estudo realizado com 21 indivíduos, que a absorção de zinco é dependente de sua concentração no lúmen, e que o jejuno foi a porção intestinal onde ocorreu maior absorção.

A captação de zinco pela superfície da borda em escova é regulada homeostaticamente por mecanismos de difusão e processos mediados por carreadores. Em situações de baixa ingestão ocorre aumento da capacidade de transporte por carreadores, e diante da alta ingestão alimentar, torna-se proeminente um mecanismo de difusão passiva sem saturação ${ }^{11}$.

0 zinco presente em altas concentrações nas células pode interferir com outros processos metalo-dependentes ou inibir proteínas. Assim, a tioneína (T) se acopla ao zinco e age como marcador bioquímico que controla a concentração do zinco. Um aumento na concentração de zinco disponível, induz a síntese de tioneína, por meio da ação do zinco sobre os fatores de transcrição zinco-dependentes, formando a metalotioneína (MT). Na presença de baixas concentrações de zinco na célula, o zinco é liberado da $\mathrm{MT}^{12}$.

A metalotioneína é uma proteína que contém 60 a 68 aminoácidos, dos quais 20 são cisteínas. Todos os 7 átomos de zinco presentes na proteína, estão ligados nestas moléculas de cisteínas, distribuídos em 2 domínios da proteína ${ }^{12}$.

Outra proteína presente na mucosa intestinal, constituída de 77 aminoácidos em sua cadeia, com 7 resíduos de cisteína, é a CRIP (proteína intestinal rica em cisteína), que se liga ao zinco na função de carreador intracelular, aumentando a velocidade de absorção ${ }^{13,14}$.

Após a absorção, o zinco é liberado pela célula intestinal, passa para os capilares mesentéricos e é transportado no sangue portal, sendo captado pelo fígado e subseqüentemente distribuído para os demais tecidos.
0 zinco é perdido do organismo por meio dos rins, da pele e do intestino. As perdas endógenas intestinais podem variar de 0,5 a 3,0 mg/dia. Sob condições normais, $95 \%$ do zinco da fração filtrável do plasma é reabsorvido na parte distal do túbulo renal. As perdas urinárias variam de 300-600 mg/dia, influenciadas por mecanismos de secreção no túbulo proximal do néfron ${ }^{7,14}$.

Os genes envolvidos no transporte deste mineral estão começando a ser clonados, e todos codificam proteínas na membrana celular, muitos apresentando um domínio intracelular rico em histidina. O gene do transportador ZnT-1 foi o primeiro a ser clonado, tendo sido descoberto em 1995 por Palmiter \& Findley. Está associado com o efluxo de zinco, sendo encontrado em vários tecidos, incluindo intestino, rins e fígado. A expressão do gene para este transportador no intestino é bem maior no duodeno e jejuno. Existem ainda o ZnT-2 presente no intestino, rins e testículos, ZnT-3 presente nos testículos e cérebro e grandes quantidades de ZnT-4 nas glândulas mamárias, podendo estar envolvido na secreção de zinco no leite ${ }^{15,16}$.

Liuzzi et al. ${ }^{17}$, observaram que com suplementação de zinco, a expressão do RNAm para ZnT-1 e ZnT-2 foi elevada no intestino, fígado e rim, mostrando que a expressão desses transportadores ocorre em resposta às condições fisiológicas relativas ao zinco.

A mutação no gene ZnT-4 provocou uma diminuição do transporte do zinco ao leite durante a lactação. Além disso, Michalczyk et al. ${ }^{18}$ detectaram a expressão de do is outros membros da família do ZnT-4, nas células epiteliais das mamas, que estão envolvidos no transporte do zinco para o leite materno.

Sekler et al. (2002) $)^{19}$ mostraram que no córtex cerebral e cerebelo, há uma elevada expressão do gene para ZnT-1, promovendo assim a homeostasia do zinco, evitando um influxo excessivo de zinco nos neurônios, o que pode causar morte neuronal. 


\section{Avaliação do estado nutricional relativo ao zinco}

O conteúdo total de zinco no organismo varia de $1,5 \mathrm{~g}$ a $2,5 \mathrm{~g}$, estando presente em todos os órgãos. Concentra-se nos ossos, músculos voluntários, fígado e pele $(90 \%)$ ). A concentração de zinco na massa corpórea magra é de aproximadamente $300 \mu \mathrm{g} / \mathrm{g}$ e no osso uma concentração de 100 a $200 \mu \mathrm{g} / \mathrm{g}$. É também encontrado no pâncreas, rins e em outros tecidos e fluidos corporais como próstata, espermatozóides, diversas partes dos olhos, cabelos e unhas, onde as concentrações mais altas foram observados na coróide do olho $(274 \mu \mathrm{g} / \mathrm{g})$ e nos líquidos prostáticos (300 a $500 \mu \mathrm{g} / \mathrm{mL}$ ). No sangue, cerca de $80 \%$ do zinco é encontrado nos eritrócitos, $16 \%$ no plasma ligado principalmente à albumina $(70 \%)$ e $\alpha 2$-macroglobulina. A circulação representa a menor parte do total de zinco do organismo, e o turnover plasmático é o mais elevado. A concentração plasmática normal é de aproximadamente $100 \mu \mathrm{g} / \mathrm{dL}$ e apesar de representar apenas cerca de $0,1 \%$ do conteúdo corporal, é a fonte primária deste mineral para todas as células, tendo uma dinâmica rápida e estando sob controle homeostático $0^{5,7,14}$, contrapondo com os valores normais de zinco no organismo ${ }^{20}$ (Tabela 1).

Tabela 1. Valores normais de zinco no organismo.

\begin{tabular}{lc}
\hline Compartimento & Concentração normal de Zinco \\
\hline Plasma & $>70 \mu \mathrm{g} / \mathrm{dL}$ \\
Eritrócitos & $42,2 \pm 5,6 \mu \mathrm{g} / \mathrm{g}$ hemoglogina \\
\hline Urina & $300-600 \mu \mathrm{g} / \mathrm{dia}$ \\
\hline
\end{tabular}

Fonte: Gibson ${ }^{20}$.

O zinco encontrado nos eritrócitos não reflete mudanças recentes nos níveis de zinco orgânico de um indivíduo, e é um parâmetro de estado nutricional relativo ao zinco de prazo mais longo. 0 conteúdo de zinco nestas células é expresso em termos de microgramas por grama de hemoglobina. A análise da fosfatase alcalina nos granulócitos também é um parâmetro muito útil, enquanto o nível plasmático é considerado um indicador inadequado, pois o organismo tenta conservar valores normais durante a deficiência. Apenas na deficiência grave há diminuição do zinco no plasma ${ }^{20}$.

\section{Funções}

Diversas enzimas e proteínas contendo zinco participam do metabolismo de proteínas, carboidratos, lipídeos e ácidos nucléicos, e, junto com informações geradas nas áreas de nutrição, fisiologia, medicina e bioquímica, tem-se consolidado o conhecimento do metabolismo do zinco e de suas funções. Nas enzimas, o zinco pode ter função catalítica ou estrutural. Dentre as aproximadamente 300 enzimas das quais o zinco faz parte estão, a anidrase carbônica, que foi a primeira a ser descoberta, fosfatase alcalina, carboxipeptidases, álcool desidrogenase, superóxido dismutase, proteína $C$ quinase, ácido ribonucléico polimerase e transcritase reversa2,3,7,14.

O zinco está envolvido na estabilização de membranas estruturais e na proteção celular, prevenindo a peroxidação lipídica. 0 papel fisiológico do zinco como antioxidante é evidenciado por 2 mecanismos: proteção de grupos sulfidrilas contra oxidação, como ocorre com a enzima $\delta$-ácido aminolevulínico desidratase e na inibição da produção de espécies reativas de oxigênio por metais de transição como ferro e cobre. 0 zinco participa da estrutura da superóxido dismutase (SOD), sendo a atividade desta enzima reduzida pela deficiência deste mineral14,21,22,23,24.

0 zinco é um mineral que desempenha papel na organização polimérica de macromoléculas como DNA e RNA, e é indispensável para atividade de enzimas envolvidas diretamente com a síntese de DNA e RNA, como por exemplo a RNA polimerase. Além disso, influencia a divisão celular, por meio da atividade da dioxitimidina quinase e adenosina (5') tetrafosfato (5')-adenosina. Defeitos na síntese ou prejuízo da função do RNA mensageiro parecem ser induzidos pela deficiência de zinco ${ }^{7,14}$. 
A concentração do hormônio de crescimento (IGF-I) também diminui na deficiência de $\mathrm{Zn}^{25}$.

Outra ação atribuída ao zinco, refere-se ao estímulo pós-receptor, que aumenta a translocação dos transportadores de glicose dos seus sítios intracelulares para a membrana plasmática ${ }^{26}$.

Pacientes diabéticos apresentam hiperzincúria, o que pode levar à deficiência de zinco. No entanto, o metabolismo do zinco na diabetes ainda não foi totalmente elucidado. Pesquisas têm sido realizadas no sentido de verificar os benefícios da suplementação com Zn nestes pacientes ${ }^{27}$.

A deficiência de zinco na insuficiência renal crônica também tem sido pesquisada nos últimos anos. M afra $\&$ Cozzolino ${ }^{28}$ observaram reduzida concentração de zinco no plasma nos pacientes urêmicos, e uma concentração eritrocitária de zinco elevada, sugerindo distribuição anormal do zinco e não deficiência verdadeira.

Numa revisão Mafra $\&$ Cozzolino ${ }^{29}$ mostraram que durante a deficiência de ferro ou intoxicação por chumbo, o zinco é incorporado na protoporfirina durante a eritropoiese, formando assim a zinco protoporfirina (ZPP) ao invés do heme. Vários trabalhos têm mostrado que a concentração deste composto está elevada no sangue de pacientes com deficiência de ferro, sendo um parâmetro de alta especificidade e sensibilidade para o diagnóstico da anemia. Assim, também tem sido visto por alguns trabalhos uma correlação entre anemia e elevadas concentrações de ZPP em pacientes com insuficiência renal crônica, podendo ser uma das causas da distribuição anormal de zinco entre plasma e eritrócitos nestes pacientes ${ }^{30}$.

Considera-se que a relação entre zinco e sinais de membrana na regulação hormonal, melhora a interação entre os hormônios e seus receptores, como observado no hormônio de crescimento e prolactina. A timulina é um hormônio importante para maturação e diferenciação de linfócitos T, cuja atividade biológica depende do zinco, e já existem trabalhos mostrando o papel do zinco relacionado com timulina e diferenciação da linhagem de células T no combate à infecções oportunistas ${ }^{31-33}$.

O zinco está relacionado com as células do sistema imune, incluindo atividade das células T-Helper, desenvolvimento de linfócitos T-citotóxicos, hipersensibilidade retardada, proliferação de linfócitos $T$, produção de interleucina-2 e morte programada de células de origem mielóide e linfóide. A presença de 5'NT (ecto-5'-nucleotidase) na membrana necessita de zinco ${ }^{14,34,35}$, visto que esta enzima está presente nas subclasses de linfócitos $T$ e $B$ com maior expressão nos linfócitos B CD8+.

A diminuída produção de citocinas e interferon- $\alpha$ pelos leucócitos está relacionada a deficiência de zinco. 0 zinco induz monócitos a produzirem interleucina-1, interleucina- 6 e inibir a produção de fator de necrose tumoral, que está implicado na fisiopatologia da caquexia na Síndrome da Imunodeficiência Adquirida ${ }^{33}$.

Há evidências de que a suplementação com $Z n$ reduz o impacto de muitas doenças, pois promove melhora do sistema imune ${ }^{36,37}$. Mocchegiani \& Muzzioli32 mostraram que a suplementação com $45 \mathrm{mg} Z \mathrm{Zn} / \mathrm{dia}$ associada com administração de AZT, diminuiu a recidiva de infecções oportunistas em pacientes HIV positivo.

Existem no sistema nervoso central, neurônios que apresentam vesículas sinápticas com elevadas concentrações de zinco, sendo estes neurônios conhecidos como uma subclasse de neurônios glutaminérgicos. A pesar do seu papel no córtex cerebral ainda ser desconhecido, o fato do zinco estar presente nos botões sinápticos, implica num papel vital do zinco neste sistema ${ }^{38}$. Além disso, o zinco está envolvido com o desenvolvimento cognitivo e, apesar do mecanismo exato não ser claro, parece que o zinco é essencial na neurogênese, migração neuronal e sinapses, e sua deficiência pode afetar 0 desenvolvimento cognitivo em crianças $^{39}$.

o zinco participa do processo de adaptação da visão noturna, fazendo parte da 
estrutura de enzimas como a desidrogenase do retinol, $\alpha$-manosidase (enzima lisossomal do epitélio retinal), anidrase carbônica, colagenase corneal e leucina aminopeptidase. Vários trabalhos relatam que o zinco pode ter um papel terapêutico na prevenção e tratamento da degeneração macular. 0 zinco está envolvido com a síntese da proteína ligadora de retinol, onde promove a ligação de fatores de transcrição ao DNA para síntese desta proteína ${ }^{14}$. Crianças desnutridas em resposta à suplementação de zinco, apresentaram um aumento nas concentrações plasmáticas de vitamina $\mathrm{A}$ e de proteína ligadora de retinol ${ }^{40}$.

Estudos têm sido desenvolvidos com relação à enzima conversora de angiotensina (ECA), que é uma metaloenzima contendo dois átomos de zinco, encontrada no endotélio vascular, que tem como função primária regular a pressão sangüínea pela conversão da angiotensina I em II, que é vasoconstritora ${ }^{41}$.

A ECA também é encontrada nos testículos, porém neste caso, possui somente um átomo de zinco e não atua na regulação da pressão sangüínea. Os efeitos da deficiência de zinco, resultando na redução da atividade desta enzima, têm sido bastante explorados com relação à maturação testicular e fertilidade em geral. Estudos têm mostrado que ratos com dietas deficientes em zinco têm uma menor atividade da ECA nos testículos, onde expressam uma menor concentração de RNAm para esta enzima ${ }^{42}$.

Assim, o zinco está envolvido com o sistema reprodutivo e sua presença no testículo é fundamental à espermatogênese $e^{14,33,35}$.

\section{Deficiência de Zinco}

A primeira manifestação da deficiência de zinco, clinicamente identificada, foi a acrodermatite enteropática, uma desordem congênita que surge na infância e é caracterizada por alopécia, diarréia, lesões de pele e imunodeficiência celular.

A deficiência de zinco ocasiona primeiro uma mobilização das reservas funcionais e, com a deficiência prolongada, podem ocorrer, anorexia, pelo aumento dos níveis de norepinefrina e alterações no hipotálamo; retardo no crescimento e defeito no crescimento fetal; cicatrização lenta; intolerância à glicose pela diminuição de produção de insulina; hipogonadismo, impotência sexual e atrofia testicular; atraso na maturação sexual e esquelética; restrição da utilização de vitamina A; fragilidade osmótica dos eritrócitos; diminuição da atividade da interleucina-2; disfunções imunológicas, ocorrendo infecções intercorrentes; hipogeusia (o Zn é componente da gustina, uma proteína envolvida com o paladar); desordens de comportamento, aprendizado e memória; diarréia, dermatite e alopecia ${ }^{7,43}$.

A deficiência de zinco moderada, além da grave, tem sido cada vez mais detectada, principalmente nos países em desenvolvimento, onde estudos bem delineados têm mostrado a importância clínica deste estado de deficiência, onde se observa: retardo no crescimento, diarréia, pneumonia, malária e prejudicado desenvolvimento cerebral ${ }^{44}$.

Os índices do estado nutricional referente ao zinco, como sua concentração no plasma, células sangüíneas, cabelo e excreção urinária, diminuem na deficiência grave. Na deficiência de zinco ocorre também diminuição da atividade de enzimas como anidrase carbônica, fosfatase alcalina e carboxipeptidases ${ }^{20}$.

Estudos recentes mostram que na deficiência de Zn, ocorre um aumento do RNAm para uroguanilina no intestino, um hormônio natriurético, que se liga a guanilato ciclase $C$, causando diarréia secretória ${ }^{45}$.

Trabalhos têm mostrado que crianças suplementadas com zinco têm menor incidência de diarréia, pneumonia e malária, quando comparadas com crianças que não recebem zinco $^{46,47}$.

Durante a deficiência de zinco podem ocorrer alterações nas respostas do nervo tímpano corda, responsável pelo paladar, levando assim à hipogeusia, ocorre também linfopenia e atrofia tímica, fato que se deve ao aumento das perdas 
das células T e B na medula óssea, além disso, a deficiência de zinco pode induzir apoptose mediada por glicocorticóides o que diminui a linfopoiese ${ }^{36,48}$.

Os fatores que podem levar à deficiência de zinco são: consumo inadequado de zinco; deficiência de zinco pela nutrição parenteral total, consumo de fitatos e fibras que diminuem a biodisponibilidade de zinco; desnutrição energético-protéica (DEP); má-absorção; insuficiência renal crônica e outras doenças ${ }^{43}$.

\section{O N C L U SÃ O}

Inúmeras descobertas sobre as funções do zinco têm sido objetos de estudo como: transportadores de membrana, seu envolvimento com a apoptose, mecanismos de defesa antioxidante e seu papel nos botões sinápticos e desenvolvimento cognitivo. Várias pesquisas mostram os resultados promissores da suplementação com zinco no tratamento da diarréia, na melhora de infecções oportunistas em aidéticos, nas alterações do paladar, na melhora do hipogonodismo. 0 zinco tem um papel fundamental no metabolismo orgânico, porém, verifica-se que ainda há ainda muitas questões a serem respondidas sobre funções, homeostasia, danos causados pela deficiência, bem como, suplementação do zinco em várias situações. Assim, sugere-se que muitas pesquisas devem ser realizadas com este mineral, no sentido de mostrar cada vez mais a importância deste para a nutrição humana.

\section{REFERÊ N CIAS}

1. Szckurek El, Bjornsson CS, Taylor CG. Dietary zinc deficiency and repletion modulate metallothionein immunolocalization and concentration in small intestine and liver of rats. J Nutr 2001; 131: 2132-8.

2. Sandstead HH. Understanding zinc: recent observations and interpretations. J Lab Clin Med 1994; 124(3):322-7.
3. McCall KA, Huang $C$, Fierke CA. Function and mechanism of zinc metalloenzymes. J Nutr 2000; 130 Suppl:1437-46.

4. Food and Nutrition Board. Dietary reference intakes for vitamin A, vitamin $\mathrm{K}$, arsenic, boron, chromiun, copper, iodine, iron, manganese, molybdnum, nickel, silicon, vanadium, and zinc. Washington: National Academy of Sciences; 2001.

5. Sandström B. Bioavailability of zinc. Eur J Clin Nutr 1997; 51(Suppl 1):S17-S9.

6. Zhou JR, Erdman JW. Phytic acid in health and disease. Crit Rev Food Sci Nutr 1995; 35(6): 495-508.

7. Organização Mundial de Saúde. Elementos traço na nutrição e saúde humana. São Paulo: Roca; 1998. p.63-91.

8. Lönnerdal B. Dietary factors influencing zinc absorption. J Nutr 2000; 130:1378-83.

9. Dyck KV, Tas S, Robberecht $H$, Deelstra $H$. The influence of different food components on the in vitro availability of iron, zinc and calcium from a composed meal. Int J Food Sci Nutr 1996; 47: 499-506.

10. Lee HH, Prasad AS, Brewer GJ, Owyang C. Zinc absorption in human small intestine. Am J Physiol 1989; 256:87-91.

11. Jackson MJ. Physiology of zinc: general aspects. In: Mills CF, editor. Zinc in human biology. London: Springer-Verlag; 1989. p.323-33.

12. $M$ aret $W$. The function of zinc metallothionein: a link between cellular zinc and redox state. J Nutr 2000; 130 Suppl:1455-8.

13. Hempe JM, Cousins RJ. Cystein-rich intestinal protein and intestinal metallothionein: an inverse relationship as a conceptual model for zinc absorption in rats. J Nutr 1992; 122:89-95.

14. Vallee BL, Falchuk KH. The biochemical basis of zinc physiology. Physiol Rev 1993; 73(1).

15. McMahon RJ, Cousins RJ. Mammalian zinc transporters. J Nutr 1998; 128:667-70.

16. Cousins RJ, MCMahon RJ. Integrative aspects of zinc transporters. J Nutr 2000; 130 Suppl: 1384-7. 
17. Liuzzi JP, Blanchard RK, Cousins RJ. Differenctial regulation of zinc transporter 1,2 and 4 mRNA expression by dietary zinc in rats. J Nutr 2001; 131:46-52.

18. Michalczyk AA, Allen J, Blomeley RC, Ackland M L. Constitutive expression of hZnT4 zinc trasnporter in human breast epithelial cells. Biochem J 2002; 364:105-13.

19. Sekler I, Moran A, Hershfinkel M, Dori A, M argulis $A$, Birenzweig $N$, et al. Distribution of the zinc transporter ZnT-1 in comparison with chelatable zinc in the mouse brain. J Comp Neurol 2002; 447(3):201-9.

20. Gibson RS. Principles of nutritional assessment. New York: Oxford University; 1990. p.543-53.

21. Fairweather-Tait SJ. Zinc in human nutrition. Nutr Res Rev 1988; 1:23-37.

22. Bray TM, Better WJ. The physiological role of zinc as an antioxidant. Free Radical Biol Med 1990; 8:281-91.

23. Hasanoglu E, Altan N, Sindel S, Ongun CO, Bali M, Altintas $\mathrm{E}$. The relationship between erythrocyte superoxide dismutase activity and plasma levels of some trace elements (Al, $\mathrm{Cu}, \mathrm{Zn}$ ) of dialysis patients. Gen Pharmacol 1994; 25(1):107-10.

24. Pow ell SR. The antioxidant properties of zinc. J Nutr 2000; 130 Suppl:1447-54.

25. MacDonald RS. The role of zinc in growth and cell proliferation. J Nutr 2000; 130 Suppl:1500-8.

26. Ezaki O. Lib group metal ions $\left(\mathrm{Zn}^{2+}, \mathrm{Cd}^{2+}, \mathrm{Hg}^{2+}\right)$ stimulate glucose transport activity by post-insulin receptor kinase mechanism in rat adipocytes. J Biol Chem 1989; 264:16118-22.

27. Disilvestro RA. Zinc in relation to diabetes and oxidative disease. J Nutr 2000; 130 Suppl: 1509-11.

28. Mafra D, Cozzolino SMF. Avaliação do estado nutricional relativo ao zinco em pacientes com insuficiência renal crônica [dissertação]. São Paulo: Faculdade de Ciências Farmacêuticas; 1999.

29. Mafra D, Cozzolino SM F. Zinco protoprofirina como parâmetro de deficiência de ferro na insuficiência renal crônica. J Bras Nefrol 2000; 22:52-6.

30. M afra D, Cuppari L, Cozzolino SM F. Iron and zinc status of patients with chronic renal failure who are not on dialysis. J Renal Nutr 2002; 12: 38-41.

31. Cunningham BC, Bass S, Fuh G, Wells JA. Zinc mediation of binding of human growth hormone to the human prolactin receptor. Science 1990; 250:1709-13.

32. Mocchegiani E, Muzzioli M. Therapeutic application of zinc in human immunodeficiency virus against opportunistic infections. J Nutr 2000; 130 Suppl:1424-31.

33. Baum M K, Posner-Shor G, Campa A. Zinc status in human immunodeficiency virus infection. J Nutr 2000; 130 Suppl:1421-3.

34. Beck FWJ, Kaplan J, Fine N, Hadschu W, Prasad AS. Decreases expression of CD73 (ecto-5'-nucleotidase) in the CD8 + subset is associated with zinc deficiency in human patients. J Lab Clin M ed 1997; 130:147-56.

35. Sandstead HH, Alcock NW. Zinc: an essential and unheralded nutrient. J Lab Clin Med 1997; 130:116-8.

36. Fraker PJ, King LE, Laakko T, Vollmer TL. The dynamic link between the integrity of the immune system and zinc status. J Nutr 2000; 130 Suppl: 1399-406.

37. Rink L, Kirchner H. Zinc-Altered immune function and cytokine production. J Nutr 2000; 130: 1407-11.

38. Frederickson CJ, Suh SW, Silva D, Frederickson CJ, Thompson RB. Importance of zinc in the central nervous system: the zinc-containing neuron. J Nutr 2000; 130 Suppl:1471-83.

39. Bhatnagar S, Taneja S. Zinc and cognitive development. Br J Nutr 2001; 85:139-45.

40. Christian P, West KP. Interactions between zinc and vitamin A: an update. Am J Clin Nutr 1998; 68 Suppl:235-41. 
41. Peczkowska M, Kabat M, Janaszek-Sitkowska H, Pulawska M. Evaluation of selected parameters of zinc metabolism in patients with primary hypertension. Pol Arch Med Wewn 1996; 95(3):198-204.

42. Stallard $L$, Reeves PG. Zinc deficiency in adults rats reduces the relative abundance of testis-specific angiotensin-converting enzyme mRNA. J Nutr 1997; 127:25-9.

43. Prasad AS. Zinc deficiency in women, infants and children. J Am Coll Nutr 1996; 15(2):113-20.

44. Hambidge M. Human zinc deficiency. J Nutr 2000; 130 Suppl:1344-9.

45. Blanchard RK, Cousins RJ. Regulation of intestinal gene expression by dietary zinc: induction of uroguanylin mRNA by zinc deficiency. J Nutr 2000; 130:1393-8.

46. Black RE, Sazawal S. Zinc and childhood infectious disease morbidity and mortality. Br J Nutr 2001; 85:125-9.

47. Strand TA, Chandryo RK, Bahl R, Sharma PR, Adhikari RK, Bhandari N, et al. Effectiveness and efficacy of zinc for the treatment of acute diarrhea in young children. Pediatrics 2002; 109(5): 898-903.

48. Goto T, Komai M, Suzuki H, Furukawa Y. Long-term zinc deficiency decreases taste sensitivity in rats. J Nutr 2001; 130 Suppl:305-10.

Recebido para publicação em 5 de março de 2002 e aceito em 27 de fevereiro de 2003. 
